\title{
Research on Teaching Method of Innovative Talents of Urban Planning Speciality
}

\author{
Y.Y. JIA
}

School of Architecture and Civil Engineering, Xihua University, Chengdu, 610039, China

J.F. LU *

College of Environment and Civil Engineering, Chengdu University of Technology, Chengdu, 610039, China

\begin{abstract}
Due to lack of Innovation consciousness and innovation ability, the development of urban planning is restricted, therefore it is imperative to training more innovative talents in urban planning. As a innovation tool, TRIZ theory has been widely used in worldwide enterprises, however, there is scarce analysis on its application in training innovative talents in universities and colleges as an training method of innovative thinking and innovative ability. Regarding the shortage in training urban planning talentsproposed training methods of innovative talents of China Urban planning including: Strengthening the establishment of teaching staff of urban planning based on TRIZ theory; Initial the course of TRIZ Innovation Theory for urban planning major; Applying TRIZ theory into urban planning class.
\end{abstract}

KEYWORD: Teaching Method; Innovative Talent; Urban Planning Speciality

\section{INTRODUCTION}

Since the TRIZ theory was founded in 1946 in former Soviet Union, Over 100 colleges and universities have set the TRIZ theory course. Currently, this theory has been widely used in various developed countries. It contributed to the new product development of many big companies including Boeing of USA, general motors, South Korea's Samsung, and help to make considerable economic benefits.[1] In 2001, the TRIZ theory training was introduced and gradually generalized in China.[2] In China, TRIZ theory has been used in various fields such as aerospace engineering, military engineering, equipment manufacturing industry and bionics techniques, and helped to make substantial achievements.[3] In the application of teaching and academic research, Tsinghua university, zhejiang university, sichuan university have set course of TRIZ theory and related approach education, however, it is only explained as a course, which still has a long way to go for the establishment of innovative talents training system based on one particular subject.[5] In this paper, based on TRIZ theory, it concluded challenging problems in training innovative talents of urban planning and proposed a series of suggestions including strengthening the establishment of innovative teaching staff, opening the course of TRIZ theory, establishing the TRIZ-based course teaching method, building platform for practicing innovative thoughts, and building the TRIZ based software platform, all of which will play an important role in training students' innovative quality, innovative thought, and innovative ability.

\section{PROBLEMS IN TRAINING URBAN PLANNING INNOVATIVE TALENTS AT PRESENT CHINA}

Training innovative talents can be extended in three aspects: (1) Training innovative quality. We need to train not only the intelligent factors including imagination, observational ability, and practical operation ability, but also train the non-intelligent factors such as passion, curiosity, and hobby. (2) Train innovative thinking. We need to train both non-logical thinking (association, imagination and analogy) and logical thinking (comparison, induction, deduction and reasoning), enabling students to establish thinking habit of agility, profoundness, integrity and innovation. (3)Train innovation ability. Innovation ability is a kind of comprehensive ability, which is reflect in the process of innovation practice. To train innovation ability, we need to adopt the combination of practice and guidance so as to enable students to master innovation method and improve self-study ability.

A survey was conducted among urban planning professionals who have been graduated for nearly 10 years and diversed in fields of engineering design, 
construction, supervision and cost. The results shows that over $75 \%$ of interviewees think the engineering knowledge learnt from class is seldom used in practical work and less than 5\% think the class knowledge is very useful. It can be seen from the snapshot of the results that at current urban planning class, theory teaching is the only emphasis, leading to a severe disjoints between class knowledge and practical work. Over $90 \%$ interviewees argue that urban planning class should be integrated with practical engineering case and relevant engineering regulations, and meanwhile, it should reflect the cutting-edge and latest knowledge, absorb the new theory and technology related to urban planning from home and abroad. Due to the shortage of urban planning development history and most dynamic knowledge, students can only passively accept knowledge instead of conducting innovative and critical study with forward-looking thinking.[4] There are 3 major reasons resulting in problems in training urban planning innovative talents at present China: (1) Social factor. The impetuous Atmosphere of entire society focus only on pragmatism, utilitarianism, quickness of success, while ignore the fundamental training; (2) Political Factor. The conventional higher education formed under longterm planned economic condition has disadvantages of independency, coerciveness, unicity and encapsulation; (3) Methodology factor. The problems include over-unitary selection mode, ignorance of individual hobby, emphasis on unified training plan, narrow range of knowledge, forcefeeding teaching method with less reflection and practice but over on memorizing, as well as onesided and unfair estimation standard, which is only based on the proficiency of class knowledge.

The conventional urban planning teaching mode not only disjoints between students and practical engineering case, but also restricts the technical development and innovation of relevant industries. Therefore, we should reform the current teaching mode, apply the method with more precise target and higher operability, and adopt new urban planning teaching mode which meet more requirements of training innovative talents under current situation, and promote it in all domestic colleges and universities.

\section{METHOD OF TRAINING URBAN PLANNING TALENTS BASED ON TRIZ THEORY}

\subsection{Build Innovation-Type Urban planning Teaching Staff Based on TRIZ Innovative Theory}

The teaching staff with comparatively high innovation quality is the key for cultivation of innovative talents. Only innovative teachers can be more conducive to the implementation of innovative education and better cultivate innovation talents. In recent years, the majority of new young teachers in Chinese institutions of higher learning have doctor's degree. Although they have cultivated their innovation ability through study in the doctoral stage, but without systematic innovation theory training, there is certain limitation in their innovative thinking and innovation ability. Therefore, cultivation of urban planning professional teachers, especially the young teachers, based on the TRIZ innovation theory is needed to strengthen the learning of innovative ways, so that teachers can systematically set up their own innovation system, research the teaching mode and reform the teaching method according to the TRIZ innovation method and build an innovative quality engineering college teachers team.

In the building of innovative teaching staff, teachers must master a set of innovation principle and innovation method, and proficiently apply it in professional classroom teaching. Application of TRIZ innovation theory can enhance the innovation ability of urban planning professional teachers and can be carried out according to the following points.

1. Actively hire domestic and foreign well-known TRIZ theory experts to undertake innovative method lectures, for teachers to understand the basic contents and principles of the TRIZ theory and realize the important significance of learning innovation methods;

2. Run TRIZ theory training class for the urban planning professional teachers. Hire domestic professors with in-depth study of TRIZ theory. In 1 or 2 weeks time and in the intensive teaching mode, let learners systematically study TRIZ theory for a comprehensive grasp of the relevant methods and principles of TRIZ theory. For the relevant examples in the training process, discussion can be carried out by combining the problems that urban planning professional teachers encounter in their respective study;

3. Actively encourage and organize the teachers to participate in the meetings and training courses relevant to domestic and foreign innovation methods, to enable teachers to fully understand the present status of research and application of TRIZ theory or other innovative methods and exchange and learn from each other;

\subsection{Carry Out "TRIZ Innovation Theory" Course Construction in Urban planning Specialty}

Creative talents must have the innovation thinking, innovation spirit and innovation ability. The cultivation and improvement of their innovation ability is a systematic project, but there exist certain rules. Therefore, it is imperative to systematically carry out innovation method and innovation ability training for the college students and postgraduates. 
At present, undertaking of TRIZ theory education has just started in China and most teachers and students know few the relevant innovation method of TRIZ theory. Open "TRIZ innovation theory" as an elective course or compulsory course for the students majored in urban planning, combine the knowledge background of students majored in urban planning and systematically cultivate students' innovative thinking and innovative ability through classroom explanation and training of innovative methods, enabling students to apply the TRIZ innovation method in their learning and study for further invention and creation.

1. Open the elective course of "TRIZ innovation theory" for urban planning undergraduates. Enable students to understand and master the knowledge relevant to TRIZ theory innovation method through classroom learning and learn to apply innovative methods and principles in thinking. In order to ensure the effectiveness of classroom learning, there are no more than 20 students in each class. In addition to explanation of the basic principles of the TRIZ innovation theory, the classroom teaching mainly features discussion on the relevant innovation problems, letting students actively apply innovative method in thinking and problem solving and enhancing students' innovative thinking and innovation ability;

2. Open the compulsory course of "TRIZ innovation theory" for urban planning innovation class. Run the urban planning innovation class with training of students' creative thinking and creative ability as the purpose. Open "TRIZ innovation theory" course as a compulsory course of the innovation class to enable the students more systematically learn the basic knowledge of innovative methods. Only through systematic learning and training of innovative methods can students think about problems with innovative thinking mode in the process of problem solving and can we cultivate innovative talents in the true sense. For the course construction of innovation class "TRIZ innovation theory", the living examples of invention problems adopted in the classroom should be related to the major of urban planning, so that the student can deepen the understanding of their professional knowledge while thinking about problems with innovative methods at the same time.

\subsection{Introduce TRIZ Theory into the Classroom Teaching of Urban planning Major}

Although China actively advocates cultivation of high-quality talent, but influenced by the traditional examination oriented education system, at present, China's classroom teaching methods mainly feature direct cramming type teaching. The teaching method tends to make students form a fixed pattern of thinking, lack of creative thinking and innovation ability. The classroom teaching mode based on TRIZ innovation theory can make up for the deficiency in the traditional classroom teaching mode. The teacher can integrates the method and principle of innovation into the urban planning related classroom teaching and uses the TRIZ theory to find, analyze and solve problems for the teaching course, enabling the students to analyze the direction for possible development and evolution of future problem solving in addition to mastering the existing solutions in the textbook, thus cultivating students' creative thinking ability.

\section{CONCLUSIONS}

This paper describes in brief the development of domestic and foreign innovation methods and TRIZ's successful application in different industries, introduces the concepts and basic ideas of TRIZ theory, analyzes China's current deficiency in cultivation of innovative urban planning professional talents and puts forward the concrete methods to cultivate urban planning innovative talents with TRIZ theory: (1) strengthen innovation-type urban planning teaching staff based on TRIZ innovation theory; (2) carry out "TRIZ innovation theory" course construction for urban planning specialty; (3) introduce TRIZ theory into the classroom teaching of urban planning major; (4) build innovative method practice platform based on the TRIZ theory; (5) construct software platform based on TRIZ theory.

This article aims to promote the basic method of the invention and innovation to urban planning talents and there isn't detailed exposition of a specific knowledge point of TRIZ theory. Urban planning is a profession with strong theoretical and practical property. Under the new situation, how to improve the quality of education and establish scientific innovative talent training mode is a problem every educator is worth paying attention to and thinking about.

\section{REFERENCES}

[1] Liang, D \& Chen, M.R. 2012. The successful application and enlightenment of technological innovation based on TRIZ in samsung. Natural Science Journal of Hainan University 30(4): 51-63.

[2] Wu, J.M \& Yao, S.S. 2010. TRIZ and its Application in aviation industry. Aeronautical Science and Technology 25(5): 15-17.

[3] Zhao, J. J \& Duan, Q.Q. 2013. Research on extension and application of TRIZ innovation method in military industrial enterprises at home and abroad. Science Technology and Industry 13(12): 82-83. 
[4] Ma, W.S \& Bai, F.C. 2012. Mode reform of innovative engineering talents based on the concept of CDIO. Vocational Technology (01): 34-36.
[5] Duan, Q. Q \& Hou, G. G. 2012. A summarize of research on innovation methods at home and abroad. Science \& Technology Progress and Policy (13):158-160. 